\title{
Design of Personal Spiral Conjoint Analysis
}

\author{
Dennis Castel*, Ryosuke Saga, Hiroshi Tsuji \\ Department of Computer Science and Intelligent System, Osaka Prefecture University, Osaka, Japan
}

(Received: October 2, 2012 / Revised: February 17, 2013; July 29, 2013 / Accepted: July 30, 2013)

\begin{abstract}
In order to point out the best utility of a product (or a service), marketers need to clearly understand and measure the preference of the consumers. Among numerous marketing analysis techniques, the conjoint analysis is one of the popular tools for market research. One of the issues with this tool is the lack of feedback for the respondents. This paper proposes personal stepwise conjoint analysis based on an interactive Web-questionnaire allowing respondents to receive a diagnosis of their evaluation and giving the possibility to reconsider their evaluation. To validate our proposal, experimentation with forty-two respondents is also demonstrated. Experimental results, potential modifications and improvements are detailed in this paper.
\end{abstract}

Keywords: Conjoint Analysis, Knowledge Mining, Marketing Analysis, Self-awareness, Decision Support

* Corresponding Author, E-mail: dennis@mis.cs.osakafu-u.ac.jp

\section{INTRODUCTION}

In marketing analysis, it is a big issue to understand and measure the preference of potential customers on products or services. Among numerous marketing analysis techniques, the conjoint analysis (Orme, 2010) is one of the most popular market research tools for designing products or services. Conjoint analysis used to be done in a regular way (pen and paper) even though it was timeconsuming. However, with the help of IT science, it has become easier to collect and analyze all the respondents' answers.

Usually, respondents fill their questionnaire anonymously and give their results. In the case of an evaluation of simple profile, this method is sufficient. However, if the profile has many attributes, the respondents' answers could be inconsistent. To overcome this problem, the marketer has to interact with the respondents after each evaluation.

Marketing analysis is not only a problem of data's collection and questionnaire's design. We also need to focus on the respondent and his evaluation. How can we be sure that his answers match with his preferences? The presence of many factors (time to answer, concentration, design of the questionnaire) makes it difficult to externalize the respondent's tacit knowledge. In addition, the conjoint analysis does not allow marketers to interact with the respondents.

With the help of a full diagnosis, respondents will be able to have a better overview of their preferences. Moreover, if we give the possibility for the respondents to rectify or validate their answers, we give to marketers the possibility to get more precise preference about product (or services), and about preferences heterogeneity among respondents.

We needed an important amount of data in order to minimize potential errors. That included having more respondents or asking respondents to evaluate more profiles, which is time-consuming. The proposed spiral process can forecast answers based on respondent's preferences and past answers. This method allows the respondent to evaluate more profiles of product faster with a better precision.

First, this paper will review the background of this research and present the basics and limits of the traditional conjoint analysis. Then, this paper will present the importance of feedback and diagnosis for the respondents, and how marketers can use them. The designed Web-questionnaire for personal stepwise analysis, named CASIMIR (Conjoint 
Analysis Spiral Interactive Mining based on Regression analysis), will be explained and discussed in Section 3 . The evaluation process will be described with the help of screen image of the application. Experimentation conducted with forty-two respondents and thirty-six profiles will be presented, and the results will be discussed in Section 4. Finally, this paper will conclude and discuss about the future works.

\section{CONJOINT ANALYSIS AND RELATED WORKS}

When we use conjoint analysis for marketing analysis, focus must be on the product or service. We must also focus on the respondent, his preference and his behavior. The complexity of the decision-making environment is still increasing, and the traditional conjoint analysis cannot be adapted in all situations (Beynon, 2002; Durbach and Stewart, 2012). Traditionally, the conjoint analysis has been a simple questionnaire given from marketer to respondents. Then, respondents answered and sent back the questionnaire. No modification or re-evaluation was possible during the process. Therefore, we had no information about how respondents understood the questionnaire. Moreover, the respondents could not draw conclusions of his evaluations.

One solution was to use a system that can be adapted to the respondent and his behavior. Improvement in context awareness recommender system allowed us to collect much information on respondents (Felfernig et al., 2011). However, behind this research, we wanted to include the respondents in the analysis process. In the case of a service analysis, the results could be important not only for the marketers but also for the respondents (Tsuji et al., 2007).

The notion of community can be major point in knowledge acquisition (Felfernig et al., 2008). The possibility to see other users' responses can influence our own evaluation. It is interesting to see how far a respondent can be influenced by other results. With all the data about respondents collected, we can specify and display the category of results in a social norm comparison (Dennis and Hiroshi, 2011).

With the traditional way of conjoint analysis, the marketer was unable to control the environment of the survey. With the proposed Web-based system, we let the respondent correct and improve his evaluation, in order to get more precise results (Sheng and Furukawa, 2009).

\section{CONJOINT ANALYSIS INTRODUCTION}

\subsection{Basics and Definitions}

Conjoint analysis is a technique used to determine the average total utility of a product and per extension, understand respondents' choice. The advantage is that the conjoint analysis is directly based on realistic choices provided mostly by non-Web-based questionnaire survey, as shown in Figure 1. The traditional conjoint analysis allowed the designer to determine which combination of limited attributes is preferred for decision-making.

Marketers design attributes and their levels of product's profiles (Table 1). With only five attributes of two levels, thirty-two different profiles can be created. Because evaluating thirty-two profiles for one respondent can be time-consuming, marketers use orthogonal arrays to select the minimum number of profiles that need to be evaluated (Orme, 2010). The more levels of attributes are added, the greater the number of profile increase in the survey, and the more difficult it will be for the respondents to rate every profile (Cheng, 2000). Marketers send the designed questionnaire to a group of respondents.

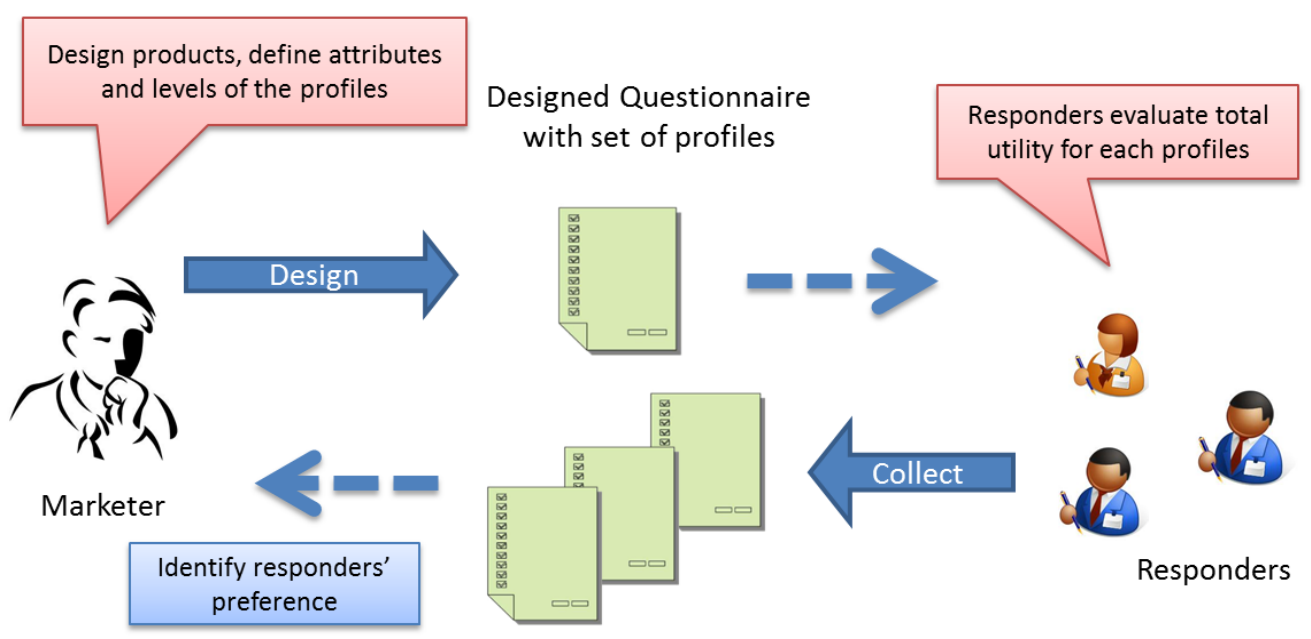

Figure 1. Traditional conjoint analysis process. 
Table 1. An example of product's description

\begin{tabular}{lcc}
\hline \multicolumn{1}{c}{ Attribute } & Level 1 & Level 2 \\
\hline Rent $(¥)$ & 15,000 & 35,000 \\
Room size $\left(\mathrm{m}^{2}\right)$ & 11 & 23 \\
Internet & Yes (free) & No \\
$\begin{array}{l}\text { Distance from school } \\
\text { (min walk) }\end{array}$ & 5 & 30 \\
Common shower rom & Common & No preference \\
\hline
\end{tabular}

After rating each profile (different methods can be used: choice-based, adaptive or full-profile conjoint analysis; Orme, 2010) the questionnaires are collected and the data analyzed (Figure 1).

Conjoint analysis calculates the relative importance rate and the partial utility of attributes. This analysis is mainly done by regression analysis, a statistic method allowing to express the relationship between a dependent variable $U_{i}$ (here the total utility of a product) and independent variable $u_{k}^{j}$ (the partial utility of the attribute). In the case of two levels attribute, as in Table $1, \beta_{i k}^{j}$ can take two values 0 or 1 depending of the two levels. If the rent of the profile 1 is equal to $¥ 15,000$, then $\beta^{¥ 15,000}{ }_{\text {rent } 1}$ will be equal to 0 . In the second case, rent value is $¥ 30,000, \beta^{¥ 30,000}{ }_{\text {rent } 1}$ is 1 . The sum of partial utility decides the range of the total utility of the profile. It can be expressed with the following linear regression model:

$$
\bigcup_{i}=\sum_{j} \sum_{k} \beta_{i k}^{j} u_{k}^{j}+u_{0}+\varepsilon, i=1, \cdots, n
$$

With:

$i \quad$ : profile number

$U_{i} \quad$ : total utility for profile $i$ $\beta_{i k}^{j}$ : 0 or 1 decided by orthogonal planning for profile $i$ where $j$ is level for attribute $k$ (example is shown in Appendix 1)

$u_{k}^{j} \quad$ : partial utility for level $j$ of attribute $k$

where $\quad \sum_{j} u_{k}^{j}=0$

$u_{0} \quad$ : base utility (constant)

$\varepsilon \quad$ : error term

Once we collected all the $U_{i}$ from respondents, and calculated all the $u_{k}^{j}$ with regression analysis (Aczel and Sounderpandian, 2005), we can evaluate $u_{0}$ as follows:

$$
u_{0}=U_{i}-\sum_{j} \sum_{k} \beta_{i k}^{j} u_{k}^{j}-\varepsilon
$$

Further, after calculating $u_{k}^{j}$ and $u_{0}$ (Formula 2), we can change partial utilities $u_{k}^{j}$ of a profile and calculate this new solution with regression analysis, as the new total utility $\hat{U}_{i}$ of this profile. This new calculated total utility can be forecasted to the respondents. The value of the constant $u_{0}$ is an important parameter, which can be used to evaluate the relative preference strength of the respondent's responses.

We also can evaluate the utility range $u r_{k}$ (difference of minimum and maximum partial utility per attribute) and the attribute importance $I_{k}$ (as shown with Formulas 3 and 4). Attribute importance is a measure in percentage describing the respondent's importance for an attribute.

$$
u r_{k}=u_{k_{\max }}-u_{k_{\text {min }}}
$$

With:

$u_{\text {kmax }}$ : partial utility maximum of attribute $k$

$u_{k m i n}:$ partial utility minimum of attribute $k$

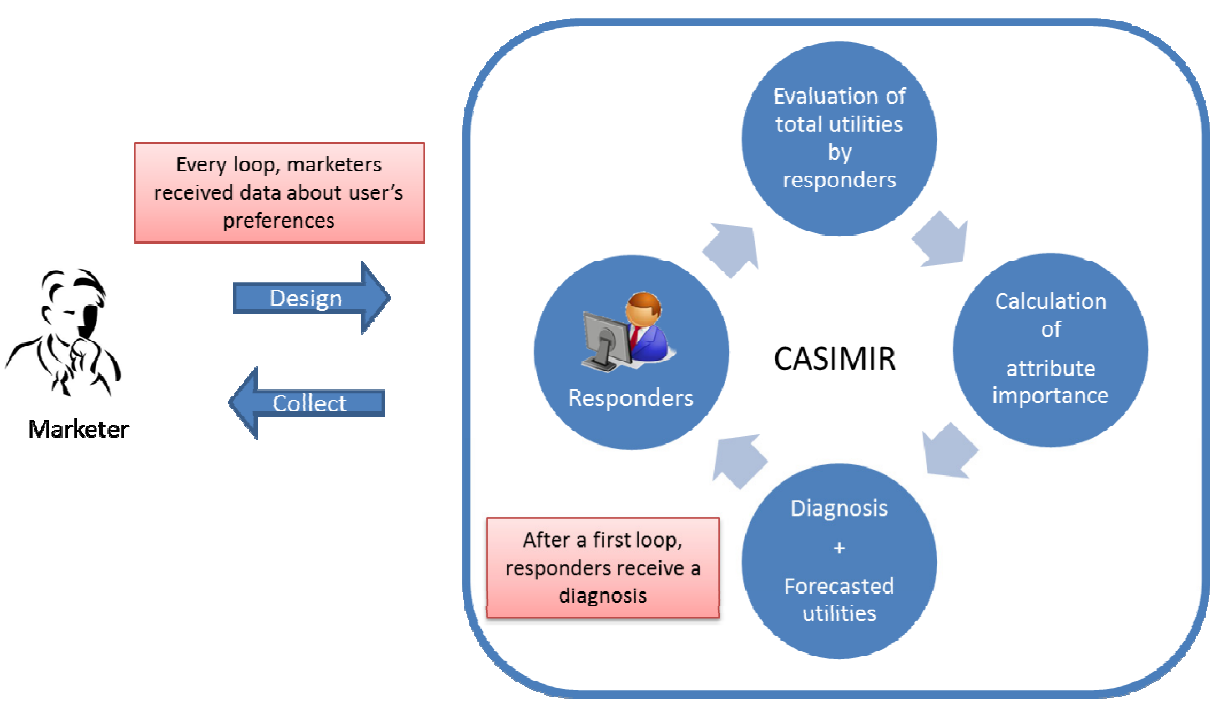

Figure 2. Personal spiral process for conjoint analysis. CASIMIR: Conjoint Analysis Spiral Interactive Mining based on Regression analysis. 


$$
I_{k}=\left(\frac{u r_{k}}{\sum_{i} u r_{i}}\right) \times 100
$$

It could be difficult for the respondent to give a good value - depending on the amount of profiles or attributes, on survey condition, on the faculty to evaluate the product. However rating each profile is a faster method than comparing each profile side-by-side (Wierenga, 2010). This questionnaire is not easy to design, so it needs more work and preparation for the marketer.

\subsection{Limits and Possible Directions}

As described above, the conjoint analysis is a popular method for marketing analysis. However, we can notice several limits with this method from the point of view of the marketers but also for the respondents. With an important amount of attributes and levels, an absence of feedback or possibility to modify his evaluation or even to have a diagnosis of his evaluation can generate inconsistent results.

A complex profile with a significant number of attributes and levels may be difficult for the marketers to design and for the respondents to evaluate in a short time. If the respondent could have some forecasted total utilities, he could use these values to evaluate complex profile, or evaluate many profiles faster. This method can give the marketer a larger amount of data, meaning more material for his analysis.

Usually with the conjoint analysis, the evaluation is done anonymously. There is no system for the respondent to reconsider his evaluation. Moreover, if he has to answer several questionnaires, it is almost impossible to use his past answer.

Marketers also design the conditions of the survey such as the time limit and the number of profile. These conditions of evaluation can influence the respondent during his evaluation. Without feedback, the respondents cannot have an overview of their evaluation. In the case of evaluation of service (like offshore software outsourcing; Tsuji et al., 2007), the interest for a special attribute can be important.

With a diagnosis of their evaluations, marketers can learn more about their preferences. It can also be an opportunity for them to realize they made some mistakes during their evaluation (and gave inconsistent results).

\section{OVERVIEW OF PROTOTYPE SYSTEM}

\subsection{Importance of Personal Spiral Conjoint Analysis}

Personal spiral conjoint analysis allows the respondent to have a real interactivity during the evaluation. He can rate his profile on his own and can receive personal diagnosis.

We call this system personal, because after each evaluation of the respondents, we collect all the results. With this collection of data, we can forecast the total utility values and attribute importance for the respondent. When this information is shown to him, he can review his choice, and possibly detect errors in his past evaluation. Seeing his diagnosis after he disregarded an attribute during the first evaluation, the respondent can attach more

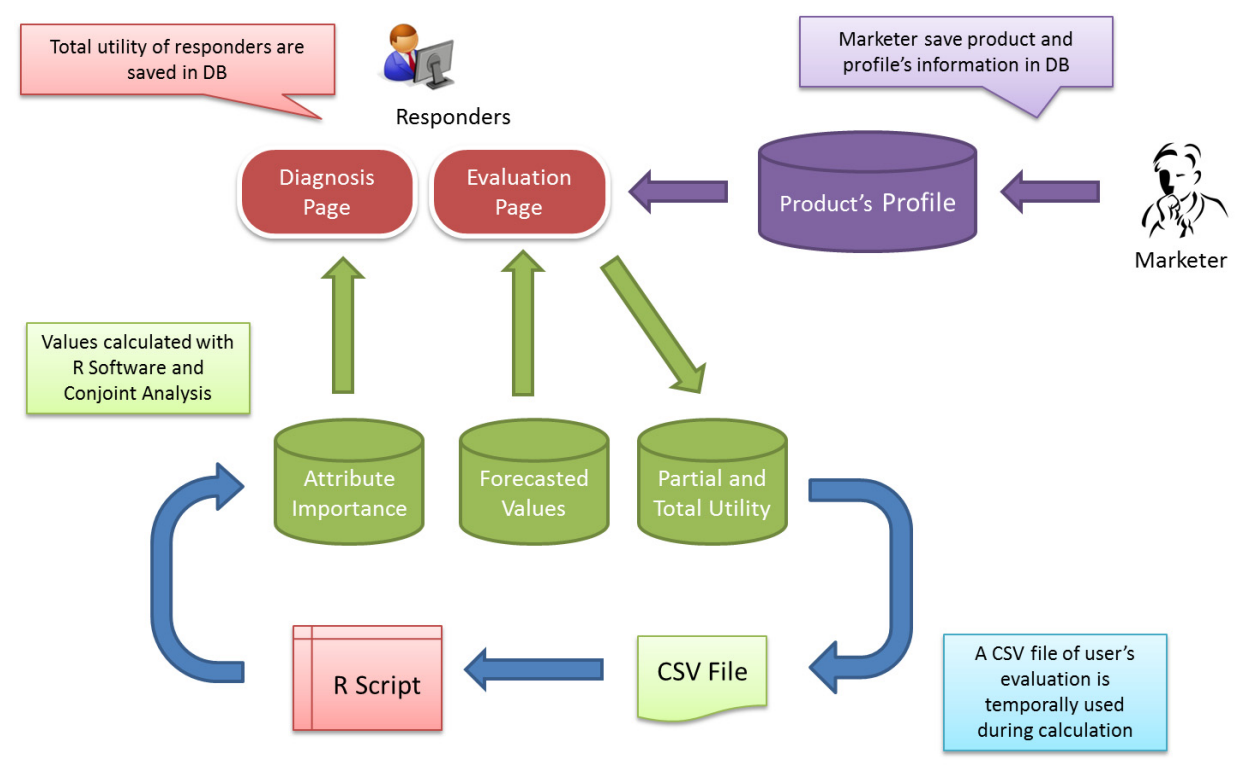

Figure 3. Architecture of CASIMIR (Conjoint Analysis Spiral Interactive Mining based on Regression analysis). CSV: comma separated values. 
importance for this attribute during the second evaluation.

The spiral process can be understood since after each evaluation, diagnosis will help respondents to rate more profiles with a better precision. This interactivity with the respondent will help him easily respond to an important amount of profiles.

We saw that with conjoint analysis, if the number of attributes of a product or the number of levels for one attribute increases, the total number of possible profiles also increases considerably (Sheng et al., 2008). For the respondent, it becomes more complicated to rate precisely all the profile. Some research tended to prove that if the amount of parameters, or the amount of profiles is too high, the respondent has difficulty giving an accurate consistent evaluation (Tiwana and Bush, 2007). With personal spiral conjoint analysis, we can reduce this difficulty by forecasting results in order to facilitate the evaluation. Table 2 summarizes the differences between these two methods.

\subsection{Presentation of CASIMIR}

In the previous section, we presented the main part of the personal spiral conjoint analysis, and now, we will introduce our system CASIMIR. With the help of this Web-based questionnaire, our idea is to forecast the total utility, attribute importance and other personal information in a diagnosis delivered after his evaluation.

In opposition to some conjoint analysis surveys which are anonymous, respondents using this system have to $\log$ in, allowing marketers to trace each of his evaluation.

Marketers can implement product or service's profile

Table 2. Comparison table

\begin{tabular}{|c|c|c|}
\hline Attribute & $\begin{array}{l}\text { Traditional conjoint } \\
\text { analysis process }\end{array}$ & $\begin{array}{l}\text { Personal spiral conjoint } \\
\text { analysis progress }\end{array}$ \\
\hline $\begin{array}{l}\text { Forecasted } \\
\text { total utility }\end{array}$ & $\begin{array}{l}\text { No forecasted total } \\
\text { utility for } \\
\text { responders }\end{array}$ & $\begin{array}{l}\text { Presence of fore- } \\
\text { casted total utility } \\
\text { in order to help } \\
\text { responders }\end{array}$ \\
\hline Diagnosis & $\begin{array}{l}\text { No diagnosis, or } \\
\text { feedback for } \\
\text { theuser }\end{array}$ & $\begin{array}{l}\text { Presence of } \\
\text { diagnosis and } \\
\text { feedback for the user }\end{array}$ \\
\hline $\begin{array}{l}\text { Modification } \\
\text { of score }\end{array}$ & $\begin{array}{l}\text { No possible to } \\
\text { modify/improve } \\
\text { past score }\end{array}$ & $\begin{array}{l}\text { User can modify / } \\
\text { improve his past } \\
\text { score }\end{array}$ \\
\hline Survey & $\begin{array}{l}\text { Designed only for } \\
\text { marketers only }\end{array}$ & $\begin{array}{l}\text { Designed for } \\
\text { marketers but also } \\
\text { for responders }\end{array}$ \\
\hline $\begin{array}{l}\text { Inconsistent } \\
\text { results }\end{array}$ & $\begin{array}{l}\text { Survey with high } \\
\text { risk of inconsistent } \\
\text { results }\end{array}$ & $\begin{array}{l}\text { Long-term survey } \\
\text { with how risk of } \\
\text { inconsistent results }\end{array}$ \\
\hline
\end{tabular}

in the database and determine how many attributes and levels is needed for surveys All these data are shown in the evaluation page (Figure 2). An evaluation page represents a set of profiles - size of set is also determined by the marketers.

After the first evaluation, scores are registered in the database. Each total utility is linked to a respondent, a set and the number of evaluations, making it possible to trace and analyze the evolution of respondent's evaluations. With the freeware $\mathrm{R}$, a powerful software for statistical computing (Gentleman and Ihaka, 2012), we calculate the slope of independent variables $u_{k}^{j}$, attribute importance $I_{k}$ and forecasted total utility $\hat{U}_{i}$ and base utility $u_{0}$.

These last values are displayed in the diagnosis page (Figure 3). It is important to remark that the diagnosis page is designed for the respondents, not for the marketers. With this page, the respondent can check and understand his previous evaluation, find his favorite profile and get a feedback of his next evaluation.

For each evaluation, we use the forecasted total utility to help the respondent to rate a larger amount of profile with a more precise score, as explained in the following section.

\section{EXPERIMENTATION}

\subsection{Plan of Experimentation}

In the last section, we designed the personal spiral conjoint analysis. CASIMIR let us validate our method. For the experiment, we will observe the difference between the respondent's total utility and personal forecasted total utility for each evaluation, to point out the influence of this system on respondent's choice. We will also analyze the evolution of the base utility $u_{0}$ in order to evaluate the consistency of responses after each evaluation. Finally, we will follow a t-test on collected partial utilities of the first and third evaluation to evaluate potential respondent's preference modification.

For experimentation, let us select the "Dormitory" product. We create three sets of profiles with orthogonal arrays. A set is composed of twelve profiles (an example is shown in Appendix 1). We ask forty-two respondents to evaluate a set of profiles three times (fourteen respondents for each profile).

After $\log$ in, the respondent accesses the first evaluation page. During the first evaluation, he can evaluate the profiles with the total utility $U_{i}$ from zero (worst) to five (favorite) with a step of one. After validating his evaluation, he can consult his first diagnosis. On this page, he can consult his main preferred profile and each attribute importance.

We ask all the respondents to wait thirty minutes between two evaluations. To be sure that the respondent 
would not be influenced by a set of profiles, we designed three set of twelve profiles. Each set has different profiles and has been attributed to respondents.

A profile is composed of five attributes with three levels (fifteen independent variables $u_{k}^{j}$ ). Several tests have been conducted to design this profile. Indeed, with less attributes or levels, there is less profile to evaluate, and the traditional conjoint analysis is sufficient for the marketers. However, with more attributes or levels, the actual regression model (Formula 1) does not give valuable results. The forecasted total utilities $\hat{U}_{i}$ is equal to the previous total utility $U_{i}$ given by the respondent. He

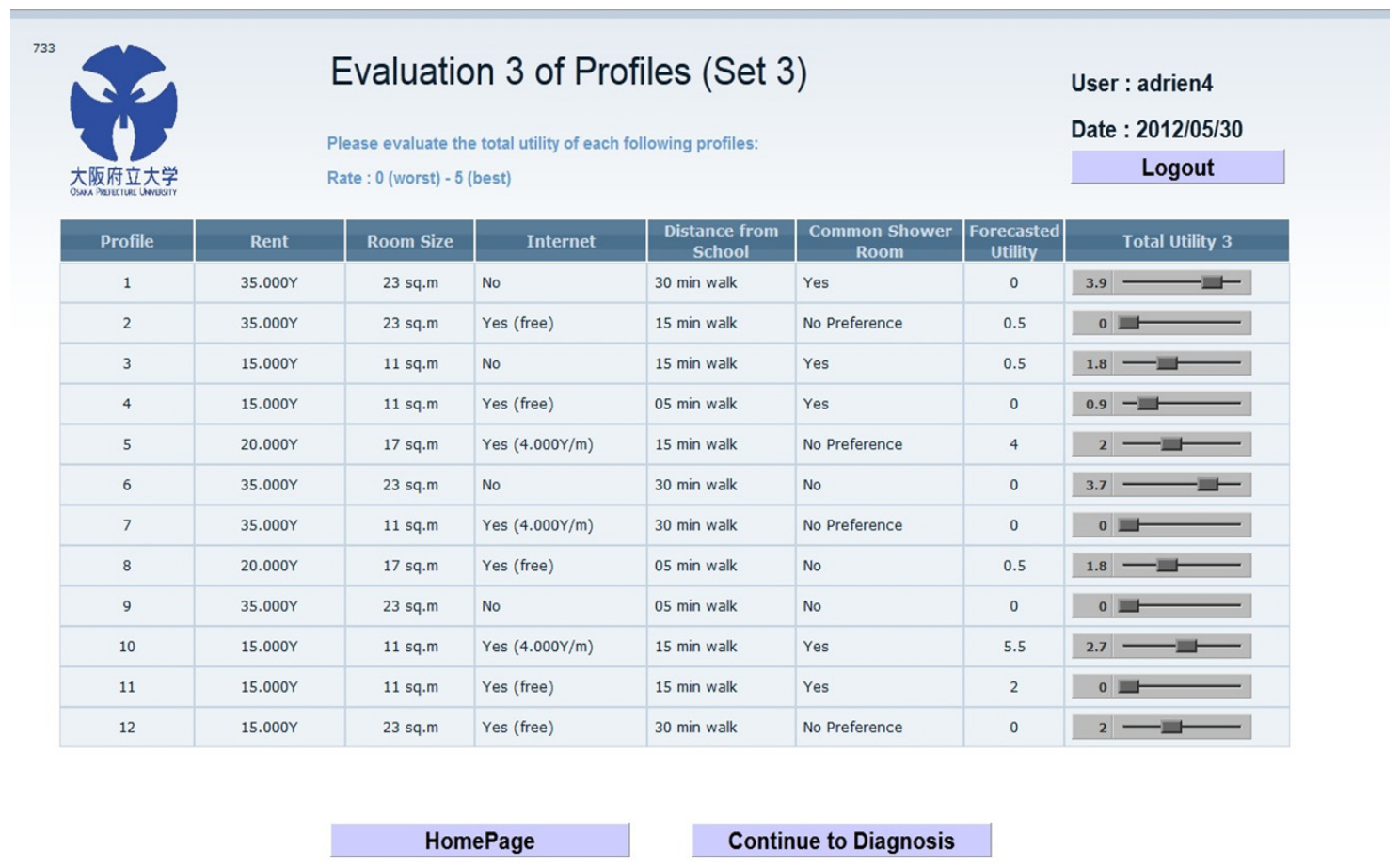

Figure 4. An example of screen: evaluation page.

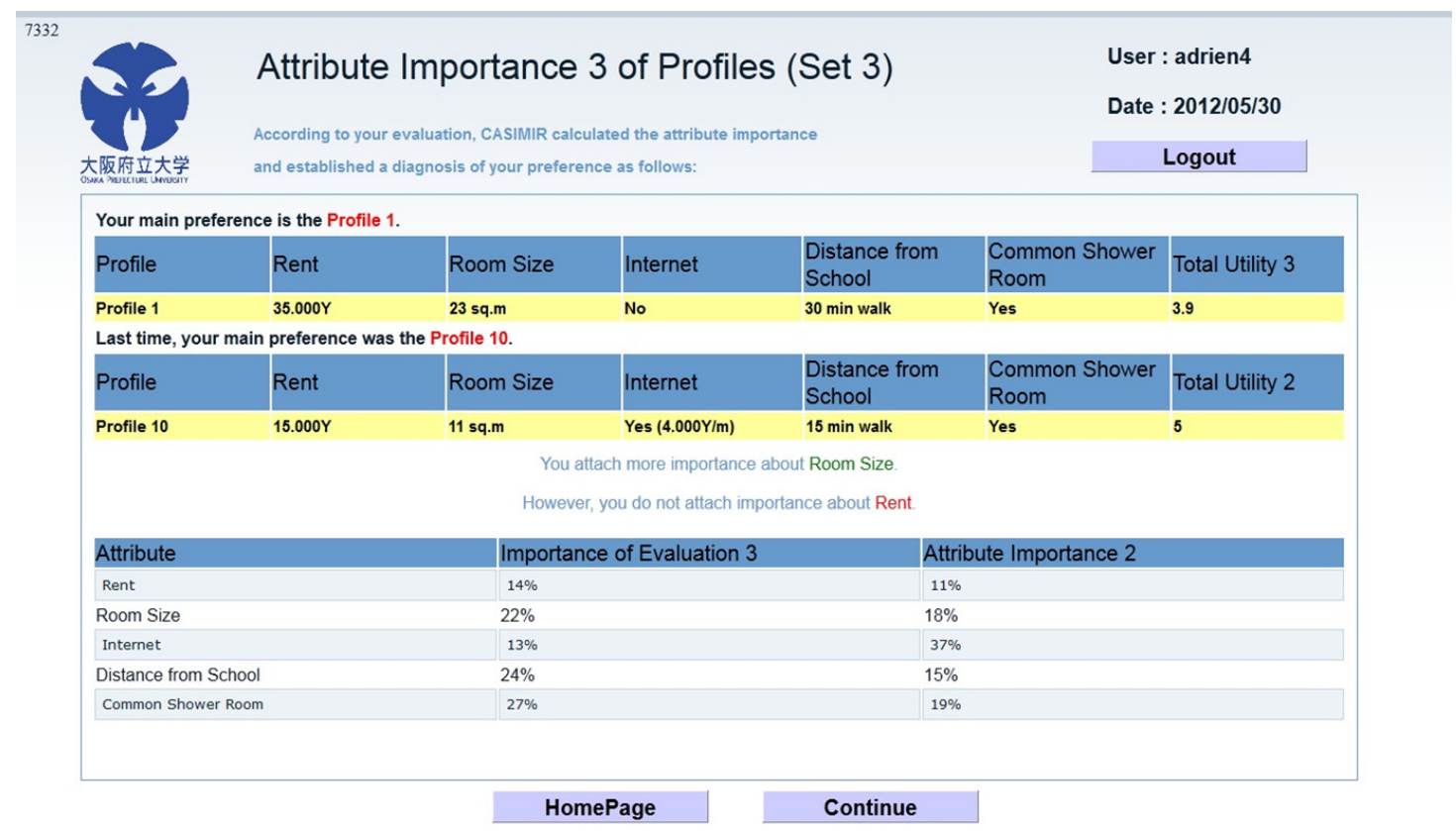

Figure 5. An example of screen: diagnosis page. 
does not have the possibilities to reconsider his score.

For the second evaluation, the same set of profiles is used, but the evaluation is slightly different. For this iteration, the score $U_{i}$ includes zero to five, but this time with a step of 0.5 . This more precise step forces the respondent to reconsider his past evaluation. As shown in Figure 4 , for each profile a forecasted total utility $\hat{U}_{i}$ has been calculated based on his evaluation. Showing these values as well as the past total utilities allows the respondent to re-evaluate the profiles more precisely and with less difficulty.

Then, a new diagnosis page is displayed as shown in Figure 5. This time, the preferred profile and attribute importance from the first and second evaluation are displayed, allowing the respondent to follow the evolution of his evaluation.

For the third evaluation, the step of score is 0.1 . Once again, the respondent can use his past total utilities and the forecasted total utilities to evaluate the profiles. At the end of the evaluation, the respondent receives a last diagnosis, similar to the second one, containing his final information.

\subsection{Discussion of Results}

After this experimentation, we study the evolution of the differences between respondent total utilities and personal forecasted total utilities (Figure 6).

Figure 6 shows a diminution of difference between the total utilities $U_{i}$ and personal forecasted total utility $\hat{U}_{i}$ during the second and third evaluation, regardless of the set of profiles. Among the forty-two respondents, thirtyone have modified their total utilities based on the forecasted ones (difference superior at 0.1). For each evaluation the total utilities are increasingly more precise. For the third evaluation, the step is 0.1 , which can be confusing for other respondent. The forecasted values based on previous evaluations help the user to evaluate the set with large score range and numerous profiles more precisely.

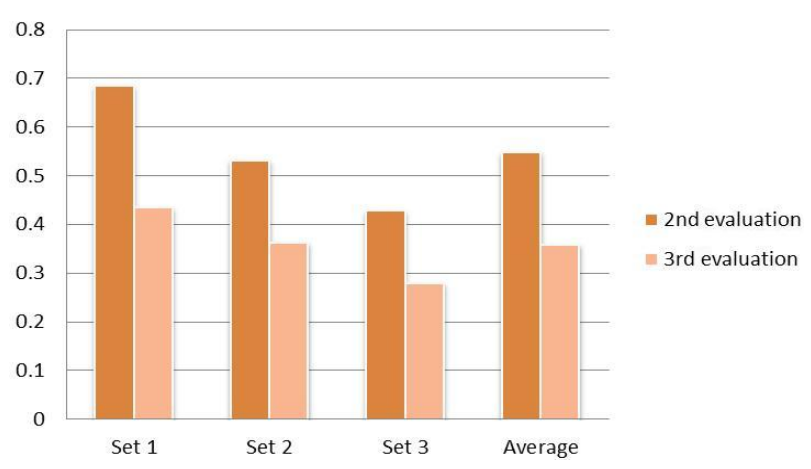

Figure 6. Differences between respondents' total utility and forecasted total utility.

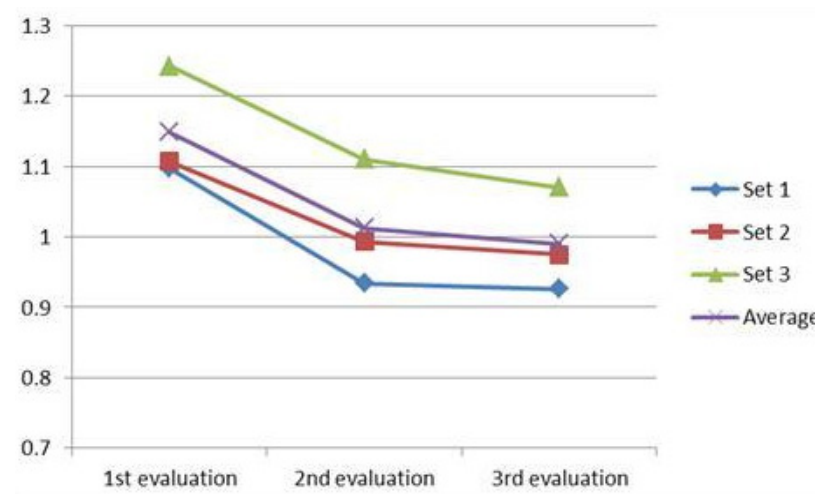

Figure 7. Evolution of respondent's base utility per evaluation.

Figure 7 shows the evaluation of base utility $u_{0}$. It seems that the respondents have different comportments depending on their ability to evaluate the set of profiles. However, the average base utility tends to decrease at the second evaluation and stabilize at the third. It can be explained by the profile evaluation system. The first evaluation has six possibilities of total utility (from zero to five), but the third evaluation has fifty-one possibilities. This large range of scores is confusing for the respondent and his base utility decrease. However, for the second and third evaluation, the respondent received personal forecasted total utilities. These forecasted values help the respondent to modify his responses even when the complexity of the evaluation increases.

One of the future works will be to determine how to translate the meaning of these values. We need to determine from which value of the base utility $u_{0}$, we can assume that the evaluation is consistent or not.

A t-test has been done with the partial utilities of the first and third evaluation. The paired two-sample t-test is a test statistic that allows validating the null hypothesis (Snedecor and Cochran, 1989). In our case, we want to evaluate if there are different partial utilities between the first and third evaluation. Partial utilities of the first

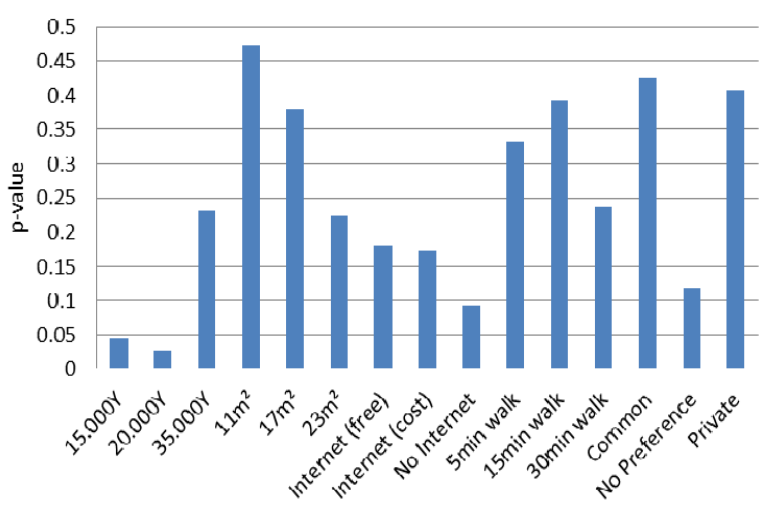

Figure 8. The p-values of partial utilities for first and third evaluations. 
evaluation are comparable to partial utilities we get with the traditional conjoint analysis.

Figure 8 shows that after the third evaluation only two partial utilities $u_{k}^{j}$ have been strongly modified (p-value superior to the significant value 0.05 ). We compared the partial utilities of the first and second evaluation, and in that case, we also get large p-values.

This means that with the presence of forecasted values and diagnosis, respondents do not change their preferences radically. For example, if a respondent has strong interest for the Room Size parameter at the first evaluation, he will also consider this parameter during the next evaluations. The CASIMIR forecasted values are based on the previous evaluations, so the recommendation will be focused on the preferred parameters of the respondents. With this method, the respondents' tacit knowledge has not been altered. However, we allow the respondent to confirm and evaluate his preference more precisely as demonstrated in Figure 6.

One possibility to influence the respondent's tacit knowledge strongly would be to show him the results of other respondents between each evaluation.

We also limited the time between evaluations to thirty minutes. The time between iteration is an important parameter, which could influence the evaluation. The more time the evaluation takes, the more the respondents can forget their past responses. Their attribute importance could be evaluated too and enlighten the respondent about his responses. The presence of forecasted total utility and past total utilities not only help him to respond faster and more precisely, but also help to remind him of his past evaluations.

\section{CONCLUSION}

This paper reviewed the traditional process of conjoint analysis and discussed the advantages of conjoint analysis, pointing out the limit of the traditional technique. Numerous profiles and attributes, conditions of the experimentation and random errors are some of the caused that lead to inconsistency of respondents' answers and imprecision for marketers' analysis.

To avoid this issue, this paper introduced the personal spiral conjoint analysis and designed a Web-questionnaire called CASIMIR. Each of these notions is trying to answer to the past issues that confronted the traditional conjoint analysis.

Our experiment has validated our first ideas. With the proposed system, the experiment has shown the positive impact of forecasted total utilities and diagnosis on the respondent choice. We also have pointed out that forecasted total utilities may also let the respondent to reconsider his evaluation and rate with more accurate total utilities.
Our diagnosis page allowed the respondent to be aware of his preferences, and with the evaluation system, he could improve his score without difficulty. Moreover, it seems CASIMIR did not influence the respondent's tacit knowledge but allowed him to confirm his first opinion, which is important for marketers.

In this paper, the evaluation is considered personal, which means that respondents received personal forecasted values and diagnosis, but it also means that the respondents cannot compare their results or interact with other respondents. This situation will be studied in another paper.

For future work, we will focus on the diagnosis page. During experiment, we realized it is difficult to quantify respondents' tacit knowledge. In our next experimentation, respondents will have to evaluate different sets of profiles rather than re-evaluate the same set. It will allow us to advise respondents about their favorite profiles with the help of forecasted total utilities and diagnosis. A new version of CASIMIR will allow generating different kinds of products (or services), in order to validate our system with different cases. Again, a larger number of participants will be required in order to avoid lack of data in our analysis.

\section{ACKNOWLEDGMENTS}

This work was partially supported by Japanese KAKENHI-C (23500049) and KAKENHI-A (13370017). The authors would like to express sincere thanks to Mr. Adrien Vella, Ms. Wei Fei, Ms. Miho Yoshihara, Mr. Kenji Fukuoka, and Mr. Ken Nishio for their assistance.

\section{REFERENCES}

Aczel, A. D. and Sounderpandian, J. (2005), Complete Business Statistics (6th ed.), McGraw-Hill, Boston, MA.

Beynon, M. (2002), DS/AHP method: a mathematical analysis, including an understanding of uncertainty, European Journal of Operational Research, 140(1), 148-164.

Cheng, H. A. (2010), Knowledgescapes: a probabilistic model for mining tacit knowledge for information retrieval, cited 2013 Aug 30, Available from: http:// www.cs.berkeley.edu/ jfc/papers/01/heyning/ms_kn owledgescapes.pdf.

Dennis, C. and Hiroshi, T. (2011), Preliminary experimentation about interactive spiral knowledge mining based on conjoint analysis, Proceedings of the 13th International Conference on Information Integration and Webbased Applications and Services, Ho Chi Minh City, Vietnam, 531-534.

Durbach, I. N. and Stewart, T. J. (2012), Modeling 
uncertainty in multi-criteria decision analysis, European Journal of Operational Research, 223(1), 1-14.

Felfernig, A., Friedrich, G., Jannach, D., and Zanker, M. (2011), Developing constraint-based recommenders. In: Ricci, F., et al. (eds.), Recommender Systems Handbook, Springer, New York, NY, 187-215.

Felfernig, A., Mandl, M., and Schubert, M. (2008), Intelligent debugging of utility constraints in configuration knowledge bases. In: Informatik 2010: Service Science-Neue Perspektiven für die Informatik, Beiträge der 40. Jahrestagung der Gesellschaft für Informatik e.V. (GI), Gesellschaft für Informatik, Bonn, Germany, 767-772.

Gentleman, R. and Ihaka, R. (2012), The R project for statistical computing, cited 2013 Aug 30, Available from: www.r-project.org.

Iyengar, R. and Jedidi, K. (2012), A conjoint model of quantity discounts, Marketing Science, 31(2), 334350 .

Orme, B. K. (2010), Getting Started with Conjoint Analysis (2nd ed.), Research Publishers, Madison, WI.

Sheng, Z. and Furukawa, K. (2009), Interactive decision support web tool based on conjoint analysis. In: Takeyasu, K. and Tsuji, H. (eds.), Management Information System and Its Application, Osaka
Municipal Universities Press, Osaka, Japan, 38-58.

Sheng, Z., Nakano, M., Kubo, S., and Tsuji, H. (2008),

Risk bias externalization for offshore software outsourcing by conjoint analysis. In: Satoh, K. et al. (eds.), New Frontiers in Artificial Intelligence: JSAI 2007 Conference and Workshops, Springer, Heidelberg, Germany, 255-268.

Snedecor, G. W. and Cochran, W. G. (1989), The comparison of two samples. In: Snedecor, G. W. and Cochran, W. G. (eds.), Statistical Methods (8th ed.), Iowa State University Press, Ames, IA, 83-106.

Tiwana, A. and Bush, A. (2007), A comparison of transaction cost, agency, and knowledge-based predictors of IT outsourcing decisions: A U.S.-Japan Cross-Cultural Field Study, Journal of Management Information Systems, 24(1), 259-300.

Tsuji, H., Sakurai, A., Yoshida, K., Tiwana, A., and Bush, A. (2007), Questionnaire-based risk assessment scheme for Japanese offshore software outsourcing. In: Meyer, B. and Joseph, M. (eds.), Software Engineering Approaches for Offshore and Outsourced Development, Sprinter, Heidelberg, Germany, 114-127.

Wierenga, B. (2010), Handbook of Marketing Decision Models, Springer, New York, NY. 


\section{Apprendix 1. An example of orthogonal planning}

\begin{tabular}{|c|c|c|c|c|c|c|c|c|c|c|c|c|c|c|c|}
\hline \multirow{2}{*}{ Profile } & \multicolumn{3}{|c|}{ Rent (¥) } & \multicolumn{3}{|c|}{ Room size $\left(\mathrm{m}^{2}\right)$} & \multicolumn{3}{|c|}{ Internet } & \multicolumn{3}{|c|}{$\begin{array}{c}\text { Distance from school } \\
\text { (min walk) }\end{array}$} & \multicolumn{3}{|c|}{ Common shower room } \\
\hline & 15,000 & 20,000 & 35,000 & 11 & 17 & 23 & $\begin{array}{l}\text { Yes } \\
\text { (free) }\end{array}$ & $\begin{array}{c}\text { Yes } \\
(¥ 4,000 / \mathrm{mo})\end{array}$ & No & 5 & 15 & 30 & No & $\begin{array}{l}\text { No prefe- } \\
\text { rence }\end{array}$ & Yes \\
\hline 1 & $\mathbf{0}$ & $\mathbf{0}$ & 1 & 0 & 0 & 1 & $\mathbf{0}$ & 0 & 1 & 0 & 0 & 1 & $\mathbf{0}$ & 0 & 1 \\
\hline 2 & $\mathbf{0}$ & $\mathbf{0}$ & 1 & 0 & 0 & 1 & 1 & $\mathbf{0}$ & $\mathbf{0}$ & 0 & 1 & 0 & $\mathbf{0}$ & 1 & $\mathbf{0}$ \\
\hline 3 & 1 & $\mathbf{0}$ & $\mathbf{0}$ & 1 & 0 & 0 & $\mathbf{0}$ & $\mathbf{0}$ & 1 & 0 & 1 & 0 & $\mathbf{0}$ & $\mathbf{0}$ & 1 \\
\hline 4 & 1 & $\mathbf{0}$ & $\mathbf{0}$ & 1 & 0 & 0 & 1 & $\mathbf{0}$ & $\mathbf{0}$ & 1 & 0 & 0 & $\mathbf{0}$ & $\mathbf{0}$ & 1 \\
\hline 5 & $\mathbf{0}$ & 1 & $\mathbf{0}$ & 0 & 1 & 0 & $\mathbf{0}$ & 1 & $\mathbf{0}$ & 0 & 1 & 0 & $\mathbf{0}$ & 1 & $\mathbf{0}$ \\
\hline 6 & $\mathbf{0}$ & 0 & 1 & 0 & 0 & 1 & 0 & $\mathbf{0}$ & 1 & 0 & 0 & 1 & 1 & 0 & $\mathbf{0}$ \\
\hline 7 & 0 & 0 & 1 & 1 & 0 & 0 & 0 & 1 & 0 & 0 & 0 & 1 & 0 & 1 & 0 \\
\hline 8 & $\mathbf{0}$ & 1 & $\mathbf{0}$ & 0 & 1 & 0 & 1 & $\mathbf{0}$ & $\mathbf{0}$ & 1 & 0 & 0 & 1 & $\mathbf{0}$ & $\mathbf{0}$ \\
\hline 9 & 0 & 0 & 1 & 0 & 0 & 1 & 0 & $\mathbf{0}$ & 1 & 1 & 0 & 0 & 1 & 0 & 0 \\
\hline 10 & 1 & $\mathbf{0}$ & $\mathbf{0}$ & 1 & 0 & 0 & $\mathbf{0}$ & 1 & $\mathbf{0}$ & 0 & 1 & 0 & $\mathbf{0}$ & $\mathbf{0}$ & 1 \\
\hline 11 & 1 & 0 & 0 & 1 & 0 & 0 & 1 & 0 & 0 & 0 & 1 & 0 & 0 & 0 & 1 \\
\hline 12 & 1 & 0 & 0 & 0 & 0 & 1 & 1 & $\mathbf{0}$ & $\mathbf{0}$ & 0 & 0 & 1 & 0 & 1 & 0 \\
\hline
\end{tabular}

To help understanding orthogonal planning and its parameters, this illustrates the example of five attributes with three levels described in Section 3.1. 